\title{
Aspectos políticos e econômicos da circulação do livro didático de História e suas implicações curriculares
}

Célia Cristina de Figueiredo CASSI ANO ${ }^{1}$

R ESU m o: 0 texto aborda aspectos da circulação do livro didático, que antecedem sua entrada na escola, mas deixam marcas nos saberes que circulam na sala de aula. Para isto, apresenta um panorama das políticas públicas para o livro didático no Brasil, em 2004, e traz um estudo sobre como esses processos interferem, tacitamente, no currículo em ação, por meio dos livros didáticos de História recebidos pelas escolas públicas da cidade de São Paulo, em 2002.

Pa L av r a S- c H av e: Livro didático; Políticas públicas; Ensino deH istória.

O objetivo do presente artigo é apresentar um estudo sobre a circulação do livro didático no Brasil, na história recente do País. Tal abordagem do livro didático pressupõe levar em conta a condição de mercadoria deste produto, que contém tanto elementos da sua materialidade, ou seja, das leis de mercado, como também do seu uso, portanto, da Educação.

No campo da Educação, entender o livro didático na sua completude justifica-se, principalmente, em função do papel que este adquire no contexto escolar. Apple observa que "são os livros didáticos que estabelecem grande parte das condições materiais para o ensino ea aprendizagem nas salas de aula de muitos países através do mundo".2 Gimeno Sacristán aponta que entrea prescrição curricular e o currículo real, que se desenvolve na prática, existe uma "elaboração intermediária do mesmo, que é a que aparece nos materiais pedagógicos e, particularmente, nos livros didáticos". ${ }^{3}$

Lajolo 4 caracteriza o livro didático como o que vai ser utilizado em aulas e cursos, na situação específica da escola, isto é, de aprendizado 
coletivo eorientado por um professor. Provavelmentefoi escrito, editado, vendido ecomprado em função da escola, sendo que esse tipo de recurso didático vai ter sua importância ampliada em países como o Brasil, nos quais as condições precárias da educação fazem com que el eacabe determinando conteúdos e decidindo estratégias de ensino. Diz ainda que o livro didático é instrumento importante de ensino e aprendizagem formal que, apesar de não ser o único, podeser decisivo para a qualidade do aprendizado resultante das atividades escolares. $\mathrm{E}$, finalmente, para ser considerado didático, um livro precisa ser usado de forma sistemática no ensino-aprendizagem de um determinado objeto do conhecimento humano, normalmente caracterizado como disciplina escolar.

Apesar deacreditarmosser o livro didático um elemento prescritivochave do currículo, e daí a importância de estudá-lo, vale lembrar que o seu uso, que se concretiza na prática da sala de aula, dá-se com sujeitos específicos, em dadas condições sócio-históricas e ao lado de outros recursos (a lousa eo giz, por exemplo), tendo então esse uso a potência de subverter o prescrito, maso faz valendo-se do próprio material, isto é, de uma condição objetiva que está dada.

Ademais, estudar as relações concretizadas no processo de circulação do livro didático nos possibilita o desvelamento das relações organizacionais e interpessoais entre indústria editorial, políticas públicas e instituição escolar, que deixam marcas no uso desse produto. Vistas, então, as especificidades desse produto, nosso intuito é verificar as relações extra-escolares inerentes ao produto, que adentram os muros escolares, mas que não ficam explícitas.

Nossa intenção de abordá-lo pela sua circulação toma-o no momento posterior à sua produção, e anterior ao seu uso, queé o momento em que este produto circula, em que será comercializado. Tomamos como ponto de partida a seleção de livros didáticos que é feita na escola, porém não entramos no mérito da qualidade da escolha desse material, e sim focamos, primeiramente, questões que a antecedem, procurando entender como ela se dá, ou melhor, investigar como esse processo se materializa, assim como quem são e como atuam os sujeitos envolvidos na seleção do livro escolar. A partir disto, nossa perspectiva analítica é entender como esses processo interferem no currículo, mas tacitamente. Por conta deste objetivo, consideramos que três são as 
instâncias fundamentais nesse processo: a área comercial das grandes editoras; o Estado, especificadamente as políticas públicas para o livro didático e a escola.

N este texto, vamosenfatizar prioritariamente as ações governamentais e apresentaremos os dados referentes aos livros de H istória.

Atualmente, em 2004, no Brasil, as políticas públicas para o livro didático são representadas pelo - PNLD (Programa Nacional do Livro Didático). Este programa foi criado em 1985, tendo como objetivo a aquisição e distribuição universal e gratuita de livros didáticos para os alunos da rede pública do ensino fundamental, sendo que a política de planejamento, compra, avaliação e distribuição do livro escolar écentralizada no governo federal. Realiza-se por meio do FNDE (Fundo Nacional de Desenvolvimento da Educação), autarquia federal vinculada ao M EC ( $M$ inistério da Educação) e responsável pela captação de recursos para o financiamento de programas voltados ao ensino fundamental.

Quando direcionamos o estudo para a circulação de livros didáticos no Brasil, um dos pontos que sobressaem éo gigantismo do volume de vendas.

Isto se dá porque a educação escolar é um sistema que acontece de forma simultânea, gradual e universal, sendo o livro didático parte integrante deste processo. Pensemos que, salvo exceções, cada aluno brasileiro que está na escola utiliza um livro didático para cada disciplina, livro este que é trocado anualmente (gradualidade), sendo que todos (universalidade) o usam ao mesmo tempo (simultaneidade). Convém observar que o governo só compra livros para as áreas de Português, Matemática, História, Geografia e Ciências.

Tendo em mente esse processo, podemoster um dimensionamento do volume de livros didáticos que circulam no Brasil.

O PNLD não só éo maior programa de fornecimento de material didático do Brasil. Juntamente com os outros programas de distribuição delivro (para bibliotecas, por exemplo) em 2001, conforme afirmou M aria Helena Guimarães de Castro (Instituto Nacional de Estudos e Pesquisas Educacionais-INEP/ M EC) na mesa redonda sobre questões educacionais da atualidade, promovida pela publicação Estudos Avançados em 27/4/2001, o Brasil está situado como "o país que tem o maior programa de fornecimento de livro do mundo". 
Partindo dessas considerações, e como o estudo aqui apresentado foi delimitado espaço-temporalmentena cidadedeSão Paulo, tendo como fonte dados do PN LD/2002, é necessário que delimitemos a participação do Estado de São Paulo no PN LD federal.

Segundo Batista, ${ }^{5}$ devido à abrangência do Programa Nacional do Livro Didático-PNLD, da dificuldade para fazer a distribuição do material para todos os Estados brasileiros e com base na diretriz formulada pelo Plano Decenal de Educação para Todos (MEC/1993), o governo federal apresentou em 1995, ao Conselho Nacional dos Secretários Estaduais de Educação-CON SED, proposta de descentralização do planejamento e execução do PNLD e da participação financeira dos Estados quando a compra realizada excedesse o montante repassado pelo M inistério. Vários Estados aderiram à proposta: M inas Gerais, Espírito Santo, Goiás, M aranhão, Paraíba, Paraná, Rio de Janeiro, Rio Grande do Sul e São Paulo.

Porém, a maioria destes Estados encontrou dificuldades para operacionalizar o PNLD, principalmenteem relação ao aumento de custos em função da compra descentralizada e, conseqüentemente, à necessidade de complementação financeira com verbas estaduais. Por isso, São Paulo passou a ser o único Estado no Brasil que manteve a operacionalização do PN LD de forma descentralizada do governo federal, desde 1995.

De acordo com dados do Centro de Informações Educacionais da Secretaria da Educação do Estado de São Paulo - CIE/SEE -SP (1998), a rede pública de ensino de São Paulo é uma das maiores do mundo: em 1998 seus números abarcavam 6.086 .947 alunos, 223.288 professores, 6.074 escolas urbanas e 1.352 escolas rurais, sendo que, pelo número de funcionários, de acordo com a Organização das Nações Unidas - ONU, é a quarta maior empresa do mundo.

Como procedimentos de pesquisa fizemos um levantamento estatístico de todos os livros recebidos pela totalidade das escolas públicas da cidade de São Paulo, em 2002, de 5a à 8ạ série das disciplinas de H istória, M atemática, Geografia, Português e Ciências. Valemo-nos, como fonte, das listas de livros de 5a à 8a série entregues por ocasião do PNLD/ 2002. Além disso, entrevistamos docentes e consultamos documentos governamentais. 
Quadro 1 - Livros recebidos Estado de São Paulo/Cidade de São Paulo PNLD/2002

\begin{tabular}{|l|c|c|c|}
\hline & Estado de São Paulo & Cidade de São Paulo & ESP/CSP \% \\
\hline $\begin{array}{l}\text { Total de livros } \\
\text { recebidos }\end{array}$ & 18.991 .127 & 4.014 .502 & 21,1 \\
\hline $\begin{array}{l}\text { Escolas } \\
\text { atendidas }\end{array}$ & 9.902 & 1.443 & 14,6 \\
\hline
\end{tabular}

Fonte: CASSIANO, Célia Cristina de Figueiredo. Circulação do livro didático: Políticas públicas, editoras, escola eo professor na seleção do livro escolar. São Paulo, 2003. Dissertação (M estrado). PUC-SP.

Segundo os dados apresentados pela Secretaria da Educação do Estado de São Paulo - SEE-SP, no 60 encontro técnico nacional dos programas do livro PNLD ePNBE, o total de investimentos no PN LD/2002, de São Paulo, foi de $R \$ 83,6$ milhões, sendo que $R \$ 82,7$ milhões foram recursos provenientes do M EC eR $\$ 0,9$ milhões financiados pela SEE-SP, devido à complementação financeira pressuposta no processo de escoIha descentralizada.

Contudo, antes de apresentarmos os resultados de nosso estudo é necessário que definamos quais foram as diretrizes para a escolha do livro didático no período estudado.

Em 1993 o Brasil traçou o Plano Decenal de Educação para Todos (1993-2003), fruto de compromisso assumido internacionalmente na Conferência M undial sobreEducação para Todos, realizada em Jomtien, na Tailândia. N este evento, os países participantes se comprometeram a criar um plano que atendesseàs necessidades específicas básicas da educação de cada um.

O plano do Brasil, entre outras considerações, apontou estratégias para o livro didático; dentre elas, deu prioridade às medidas para assegurar tanto a qualidade física do livro, quanto a qualidade de seu conteúdo, visto que o princípio de livre escolha pelo professor esbarra em sua insuficiente habilitação para avaliar e selecionar. ${ }^{6}$

No mesmo ano da publicação do Plano Decenal de Educação para Todos, o M EC constituiu uma comissão para analisar a qualidade dos conteúdos programáticos e dos aspectos pedagógico-metodológicos dos 
livros que vinham sendo comprados por este ministério para as séries iniciais do ensino fundamental. Tal comissão analisou os dez livros de cada disciplina mais solicitados pelos professores das escolas públicas. Este estudo demonstrou que o MEC vinha comprando e distribuindo para a rede pública de ensino livros didáticos com erros conceituais, preconceituosos e desatual izados no tocante aos conteúdos. Como conseqüência, a partir de 1996 o M EC passou a submeter os livros didáticos a uma avaliação, cujos resultados são divulgados nos Guias de Livros Didáticos, distribuídos nacionalmente para as escolas, com o objetivo de orientar os professores na escolha do livro didático.

O governo federal, que até então se mantivera como comprador e distribuidor de livros didáticos, instituiu, dessa forma, um processo de avaliação destes livros, redefinindo o papel do MEC no PNLD. Sendo assim, as obras inscritas pelas editoras eque não fossem aprovadas seriam excluídas da compra pelo PN LD.

O que causou grande desconforto em relação à avaliação doslivros didáticos, em 1996, foi a extensa lista delivrosinscritos e excluídos, principalmente por erros conceituais. A lém do impacto da própria avaliação, até então inédita no PNLD, o fato de o MEC ter divulgado a existência da tal lista, porém adiado a sua publicação várias vezes, ocasionou um gradativo mal-estar nos interessados no resultado da avaliação, gerando manifestações de entidades diversas, tais como a Associação Brasileira de Editores de Livros - Abrelivros; a Associação Brasileira de Autores de Livros Educativos - Abrale; a Associação de Pais e Alunos do Estado de São Paulo - Apaesp; a Associação Intermunicipal dePaiseAlunos deSão Paulo - Aipa; a Câmara Brasileira do Livro - CBL eo Sindicato Nacional de Editores de Livros - Snel, entre outros.

No entender de Batista, os critérios comuns de análise dos livros das diferentes disciplinas foram: a adequação didática e pedagógica; a qualidade editorial e gráfica; a pertinência do manual do professor para uma correta utilização do livro didático e para atualização do docente. ${ }^{7}$

Como critérios eliminatórios foram definidos que os livros: não poderiam expressar preconceito dequalquer origem; não poderiam apresentar erros conceituais.

No Guia deLivros didáticospara o PN LD/2002, cuja análiseincidiu sobre os livros de 5a à 8ª série, pela primeira vez um dos critérios im- 
postos às editoras para a inscrição dos livros foi o da coleção, isto é, só puderam ser inscritas coleções completas para as quatro séries do ciclo II. Para o MEC, alterações importantes foram feitas no PNLD/2002, sendo que:

Uma delas foi a decisão de que os livros não seriam mais avaliados por série, mas por coleção, para o conjunto das quatro séries. 0 objetivo dessa modificação foi proporcionar a articulação pedagógica dos volumes que integram uma coleção didática, possibilitando, assim, o desenvolvimento curricular na escola. ${ }^{8}$

Até então, de 1996 até 1999 (em 2000 o Guia não foi editado), os livros eram avaliados isoladamente, chegando ao extremo de dentro de uma coleção para o mesmo componente curricular, alguns livros serem mal avaliados e, por conseguinte, excluídos do programa, e os outros dessa mesma coleção, bem avaliados e mantidos.

Excetuando-se esse, os outros critérios comuns de avaliação e classificação dos livros dos anos anteriores foram mantidos: correção dos conceitos e informações; correção e pertinência metodológica; contribuição para a construção de cidadania; manual do professor; e aspectos gráficos editoriais.

Quando finalizamos o levantamento dos livros recebidos pelas escolas paulistanas no PN LD/2002, alguns fatores nos chamaram a atenção, entre eles o descompasso entre a escolha dos docentes e a avaliação do Guia dos Livros Didáticos para boa parte das disciplinas; a concentração das vendas em poucas editoras e o recebimento das coleções de 5a à 8a série de forma fragmentada, inclusive de coleções que possuíam propostas metodológicas bastante diversificadas.

Em relação ao recebimento das coleções de forma fragmentada, verificamos que a SEE de SP, diferentemente das orientações do MEC, possibilitava esta alternativa para os docentes, porém como escolha, e não como imposição:

No caminho de ampliação de opções, salientamos que, embora o Guia de Livros Didáticos do PN LD 2002 do M EC organize as obras em coleções, isso não significa que a escolha deva incidir sobre toda a coleção, pois a SEE-SP optou por permitir à escola a possibilidade de adoção da coleção inteira ou a 
escol ha dediferentes obras da mesma coleção, de acordo com seu interesse. Ao analisarmos as escolhas feitas nos dois últimos anos constatamos que as mesmas têm sido diversificadas, não privilegiando a adoção de coleções, escolhendo o livro que melhor atende ao desenvolvimento do trabalho com a sua clientela. Fica, portanto, mais esta decisão para a escola: aquela em que ela própria monta sua coletânea e o acervo quemelhor apoio oferece ao seu projeto. ${ }^{9}$

O levantamento dos livros recebidos pelas 1.443 escolas públicas paulistanas nos apontou um grande número de escolas que receberam coleções fragmentadas (dois livros de uma coleção e dois de outra, por exemplo). Procuramos, então, aleatoriamente, estabelecer comunicação com algumas destas escolas, sendo que todas as escolas contatadas foram unânimes em dizer que haviam escolhido coleções inteiras nas duas opções e que ficaram decepcionadas em receber coleções mescladas entre suas primeiras e segundas opções.

Isso pode ocorrer porque as escolhas devem ser feitas em duas opções, isto é, devem ser escolhidos quatro livros como primeira opção e quatro livros como segunda opção. No caso do PNLD/2002 centralizado no governo federal, tais escol has devem incidir obrigatoriamente em duas coleções. No caso do PNLD descentralizado do Estado de São Paulo, o critério das duas opções se mantém, porém não se obriga a escolha por coleções, conforme já foi exposto. Com referência ao que consta no Guia de Livros Didáticos 2001/2002, a segunda opção é importante porque a negociação com autores e editores é feita por meio de variáveis como preço, tiragem mínima e prazo de entrega. Por este motivo, a segunda opção também tem de ser obrigatoriamente de uma editora diferente da primeira.

E é justamente neste contexto que encontramos um descompasso considerável entre os livros solicitados por grande parte dos docentes e os efetivamente recebidos nas escolas, desmanchando todo o discurso que apregoa a liberdade de escolha dos docentes e as prioridades pedagógicas na compra dos livros.

Para que os dados referentes às informações acima possam ser visualizados, optamos por apresentar os dados relativos à disciplina de História, porque tal constatação chama a atenção pela discrepância das propostas metodológicas dos livros recebidos pelas escolas. 
Os indicadores obtidos na tabulação dos livros de H istória recebidos pelas instituições escolares públicas de São Paulo apontam os livros H istória Temática (162.387) eH istória eVida Integrada (129.049) como os mais escolhidos pelos docentes paulistanos, sendo que estes livros são igualmente os mais bem recomendados no Guia de Livros Didáticos, com duas e três estrelas respectivamente, como pode ser visto no Quadro 2.

Quadro 2 - Total de vendas em História/ Avaliação do M EC - Cidade de São Paulo/ PNLD/2002

\begin{tabular}{|c|c|c|c|c|}
\hline Título & Autor & Editora & $\begin{array}{c}\text { Avaliação } \\
\text { MEC }\end{array}$ & Vendas \\
\hline $\begin{array}{l}\text { 1 - História \& companhia } \\
\text { I, II, III eIV }\end{array}$ & $\begin{array}{l}\text { Adhemar M M arques/ } \\
\text { Flávio C. Berutti / Ricardo } \\
\text { de M. Faria }\end{array}$ & Lê & * & 16.539 \\
\hline $\begin{array}{l}2 \text { - História cotidiano } \\
\text { emental }\end{array}$ & $\begin{array}{l}\text { Eliete Toledo / Ricardo } \\
\text { Dreguer }\end{array}$ & Atual & * & 13.460 \\
\hline $\begin{array}{l}\text { 3- História das cavernas } \\
\text { ao 3o milênio }\end{array}$ & $\begin{array}{l}\text { Patrícia R. Braick e M yriam } \\
\text { B. M ota }\end{array}$ & Moderna & \begin{tabular}{|c|} 
Avaliada \\
pelaCENP
\end{tabular} & 4.224 \\
\hline $\begin{array}{l}4 \text { - História do Brasil/ } \\
\text { Históriageral }\end{array}$ & $\begin{array}{l}\text { Joaci P. Furtado / M arco } \\
\text { Antonio Villa }\end{array}$ & Moderna & $*$ & 21.205 \\
\hline 5- História temática & $\begin{array}{l}\text { Andrea R. Dias M ontellato / } \\
\text { Conceição A Cabrini / } \\
\text { Roberto Catelli Jr. }\end{array}$ & Scipione & ** & 162.387 \\
\hline $\begin{array}{l}6 \text { - Jornada para o nosso } \\
\text { tempo I, II, III e IVv }\end{array}$ & Gleuso Damasceno Duarte & Lê & * & 0 \\
\hline 7 - Nas trilhas da História & $\begin{array}{l}\text { Kátia C. P. Alves / Regina } \\
\text { Célia de M oura / Gomide } \\
\text { Belisário }\end{array}$ & Dimensão & * & 7.215 \\
\hline 8 - Nova História crítica & M ario Furley Schmidt & $\begin{array}{c}\text { Nova } \\
\text { Geração }\end{array}$ & * & 0 \\
\hline $\begin{array}{l}\text { 9- Para compreender } \\
\text { a História }\end{array}$ & Renato Mocellin & Do Brasil & $*$ & 21.308 \\
\hline 10 - Saber e fazer História & Gilberto Vieira & Saraiva & * & 74.809 \\
\hline 11 - Tempos de H istória & Gleuso Damasceno Duarte & Lê & \begin{tabular}{|c|} 
Avaliada \\
pelaCENP
\end{tabular} & 0 \\
\hline $\begin{array}{l}12 \text { - Trabalho e civilização } \\
\text { - Uma História global }\end{array}$ & $\begin{array}{l}\text { Maria F. M. Antunes/ } \\
\text { Ricardo F. deAlbuquerque } \\
\text { Maranhão }\end{array}$ & Moderna & $*$ & 12.736 \\
\hline 13 - História eVida & $\begin{array}{l}\text { Claudino Piletti / Nelson } \\
\text { Piletti }\end{array}$ & Ática & \begin{tabular}{|c|} 
Avaliada \\
pelaCENP
\end{tabular} & 13.477 \\
\hline
\end{tabular}


continuação

\begin{tabular}{|c|c|c|c|c|}
\hline Título & Autor & Editora & $\begin{array}{c}\text { Avaliação } \\
\text { MEC }\end{array}$ & Vendas \\
\hline $\begin{array}{l}14 \text { - História e vida } \\
\text { integrada }\end{array}$ & $\begin{array}{l}\text { Claudino Piletti / Nelson } \\
\text { Piletti }\end{array}$ & Ática & *** & 129.049 \\
\hline $\begin{array}{l}15 \text { - História- passado } \\
\text { epresente }\end{array}$ & \begin{tabular}{|l|} 
ElianeF. Bittencourt Couto / \\
Sonia IreneSilva do Carmo
\end{tabular} & Atual & * & 23.010 \\
\hline $\begin{array}{l}16 \text { - História - edição } \\
\text { reformulada }\end{array}$ & $\begin{array}{l}\text { José Roberto M artins } \\
\text { Ferreira }\end{array}$ & FTD & * & 8.898 \\
\hline 17 - Estudo de História & Ledonias Franco Garcia & UFG & * & 1.767 \\
\hline 18 - História & MarleneOrdoñez & IBEP & * & 25.222 \\
\hline 19 - Cultura e sociedade & $\begin{array}{l}\text { Lucy R. Valentini / M aria } \\
\text { Célia Pinto Vilela / M arlene } \\
\text { Ordoñez }\end{array}$ & IBEP & * & 11.571 \\
\hline $\begin{array}{l}20 \text { - Brasil: Uma H istória } \\
\text { em construção }\end{array}$ & $\begin{array}{l}\text { José Rivair M acedo / M ariley } \\
\text { Wanderley deOliveira }\end{array}$ & Do Brasil & * & 66.826 \\
\hline
\end{tabular}

Fonte: ver Quadro 1.

Obs.: Indicam-se em negrito as coleções mais vendidas.

Porém, ao tabularmos os dados das 1.443 escolas públicas paulistanas, deparamos com um fator bastanteintrigante: a maioria das escolas que recebeu os livros das coleções citadas não as recebeu completas, isto é, recebeu dois ou três livros das coleções citadas, eo(s) outro(s) de outra coleção, dentre as possíveis opções que podem ser vistas no Quadro 2.

Tal fato nos chamou a atenção, principalmente por conta da abordagem metodológica diferenciada proposta no livro H istória Temática, única coleção que, no PN LD/2003, ofertou livros formados por quatro grandes eixos temáticos: Tempose Culturas; Diversidade Cultural eConflitos; Terra e Propriedade 0 mundo dos cidadãos.

Devido à sua proposta metodológica, os livros da Coleção H istória Temática dificilmente seriam bem articulados com os livros de outras coleções, a não ser que fossem intencionalmente escolhidos pelo docente, isto porque as outras coleções, apesar de possuírem diferenças entre si, têm mais possibilidade de interação entre elas, visto que a maioria aborda o ensino de História cronologicamente.

Do ponto de vista pedagógico, esta seleção, aparentemente feita pelos docentes, fica mais comprometida se pensarmos que tais livros foram os que obtiveram maior vendagem. 
Procuramos, então, estabelecer uma correspondência entre o descompasso das escolhas das escolas que, apesar de escolherem os livros mais estrelados, não foram ao encontro das expectativas do $\mathrm{MEC}^{10}$ no tocanteà escolha ser feita por coleções, que, como já mencionamos, queria "preservar a unidade e a articulação didático-pedagógica da escola, possibilitando, assim, o desenvolvimento curricular deforma integrada". Lembramos, também, que no caso específico das escolas do Estado de São Paulo, além das orientações do M EC (pois o Guia de LivrosD idáticos era fonte de consulta), a SEE - CEN P possibilitou a escolha por coleções inteiras ou por obras de diferentes coleções. Porém, foi enfatizado que se a escolha recaísse sobrea coleção completa seria respeitada, poiso intuito era de que a escola escolhesse os livros que atendessem adequadamente ao desenvolvimento do trabalho da escola com a sua clientela.

Apesar das considerações feitas pela SEE-CEN P no sentido de que as escolhas não precisariam recair obrigatoriamentenuma coleção completa, causou espanto constatar que grande parte das escolas paulistas optou por escolher parcialmente os livros da coleção H istória Temática, graças às especificidades metodológicas desta coleção. Este foi o motivo que nos levou a entrevistar docentes com as seguintes características: os que participaram da escolha em 2001, que atuassem em escolas localizadas em bairros diferenciados e que fossem professores de História de escolas que receberam a coleção História Temática de forma fragmentada. Nosso interesse primordial foi averiguar se realmente esta havia sido a opção da escola, isto é, receber a coleção fragmentada.

As primeiras entrevistas foram real izadas com professores que, em 2001, atuavam na EM EF Senador Milton Campos, de Brasilândia. N esta escola foram recebidos os livros de História apresentados no Q uadro 3:

Quadro 3 - Livros de História recebidos pela EM EF Sen. M ilton Campos - PNLD/2002

\begin{tabular}{|c|c|c|c|}
\hline Série & Livros & Editora & Quantidade \\
\hline $5 \underline{a}$ & História Temática & Scipione & 221 \\
\hline $6 \underline{a}$ & História Temática & Scipione & 261 \\
\hline $7 \underline{a}$ & História Temática & Scipione & 141 \\
\hline $8 \underline{a}$ & Brasil, uma História em construção & Brasil & 141 \\
\hline
\end{tabular}

Fonte: ver Quadro 1. 
Ao ser questionada sobre a procedência de tal escolha, a professora Silmar, docente de H istória dessa escola em 2002, disse que "levou um choque" com o livro de 8a série que a escola havia recebido, ou seja, Brasil: Uma História em construção:

Havíamos pedido a coleção completa deH istória Temática como primeira opção, sendo que a segunda opção, acho que foi História crítica. Quando eu entrei na sala da coordenadora, no ano seguinte, 2002, para pegar a coleção, ela não veio completa. Eu abri evi que vieram os livros de História Temática de todas as séries, porém, quando abri o pacote da 8a série, apareceu Brasil, uma história em construção. Que não tinha nada a ver. ${ }^{11}$

A professora enfatizou a escolha da coleção completa para as duas opções, como pôde ser confirmado posteriormente nos registros da escola. Ressaltou que essa coleção, por ser temática, tem uma seqüência, e que o ideal seria, inclusive, trabalhar com os alunos das 8a séries de forma articulada com o trabalho que já vinha fazendo nas outras séries.

Temos, então, que a decisão da SEE - CENP de possibilitar a escoIha parcial ou total das coleções, aparentemente bastante democrática e com objetivo de privilegiar a prática pedagógica, na verdade possibilita um subterfúgio para que a própria Secretaria da Educação negocie de forma bastante flexível com as editoras, pois não se justifica que a EM EF M ilton Campos tenha sido prejudicada na sua opção de receber a coleção inteira, visto que as condições objetivas para o atendimento de tal solicitação existiam. Esta afirmação pode ser verificada levando-se em conta que al gumas escolas receberam a coleção H istória Temática completa.

Dentre as 1.443 escolas públicas da cidade de São Paulo, 316 instituições receberam os livros da coleção História Temática, porém apenas 129 receberam a coleção na íntegra, sendo que as 187 restantes receberam somente dois ou três livros da coleção.

O bservamos na Tabela 1 a disparidade entre os volumes recebidos pela 7ạ e 8aㅗ séries. Por mais que na 8a série houvesse menos alunos, o contraste não se justifica, sendo que no caso de algumas coleções houve uma venda expressiva justamente na $8^{a}$ série, como é o caso da coleção Brasil: Uma História em construção, alvo das nossas observações anteriores. 
Tabela 1 - Coleção História Temática - PNLD/ 2002 (Cidade de São Paulo).

\begin{tabular}{c|c}
\hline Séries- ciclo II & Livros recebidos \\
\hline $5^{\underline{a}}$ & 51.412 \\
$6^{\underline{a}}$ & 37.271 \\
$7 \underline{a}$ & 88.683 \\
$8^{\underline{a}}$ & 25.898 \\
Total & 163.387 \\
\hline
\end{tabular}

Fonte: ver Quadro 1.

Outra constatação interessante pode ser feita na comparação das duas coleções que obtiveram o maior número de vendas.

Tabela 2 - Total de obras recebidas da Coleção História Temática e H istória eVida Integrada Cidade de São Paulo - PN LD/ 2002

\begin{tabular}{c|c|c}
\hline $\begin{array}{c}\text { Séries - } \\
\text { Ciclo II }\end{array}$ & $\begin{array}{c}\text { Livros recebidos } \\
\text { História Temática }\end{array}$ & $\begin{array}{c}\text { Livros recebidos } \\
\text { História e Vida Integrada }\end{array}$ \\
\hline $5 \underline{a}$ & 51.412 & 27.476 \\
$6 \underline{a}$ & 37.271 & 46.807 \\
$7 \underline{a}$ & 88.683 & 17.657 \\
$8 \underline{a}$ & 25.898 & 37.109 \\
Total & 163.387 & 129.049 \\
\hline
\end{tabular}

Fonte: ver Quadro 1.

Notamos que, no caso das coleções especificadas na Tabela 2 - justamente as mais vendidas de História - há alternância de livros mais vendidos em séries diferenciadas. Ou seja, também aqui conseguimos visualizar que as escolas não receberam as coleções completas.

Opção ou imposição? Esta foi a pergunta quenos fizemos ao deparar com tais dados.

Poderíamos considerar a hipótese de as escolas realmente terem optado pela coleção fragmentada; sendo assim, ou a maioria das escolas tenderia a estar com projetos diferenciados, ou ainda poderíamos pressupor a incapacidade do docente de escolher adequadamente o livro di- 
dático, sendo esta alternativa a mais apresentada no discurso governamental, tal como consta no M EC (1993), Batista, e até em análises internacionais, como a de Choppin. ${ }^{12}$

Porém, o que concluímos dos indicadores apresentados em relação ao recebimento das coleções fragmentadas éque na compra dos livros as considerações mercadológicas superaram as considerações educacionais, visto que todos os docentes entrevistados (de todas as disciplinas) afirmaram que as coleções foram solicitadas completas, tanto na primeira quanto na segunda opção. Enfatizamos que esta parte de nosso estudo se deu predominantemente de forma qualitativa, sendo que entrevistamosnove docentes ao todo, que confirmaram a escolha por coleção, mas consideramos que estes profissionais representam, pelo menos, os valores do grupo ao qual pertencem.

O depoimento da diretora do M ilton Campos, em relação ao recebimento das coleções de forma fragmentada, reflete o discurso dos outros docentes entrevistados. Na época da escolha dos livros em questão, 2001, ela era coordenadora pedagógica:

Lembro de ter recebido as coleções fragmentadas. É terrível, porque o trabalho fica sem continuidade. Inclusive, você escolheu a coleção porque gostaria que houvesse a continuidade, eessa foi cortada. Seria melhor vir a $2^{\mathrm{a}}$ opção desde que inteira, justamente por causa da continuidade. ${ }^{13}$

O professor paulistano, foco do nosso estudo, subverte a prescrição na sua prática, utilizando o livro didático recebido de modo a reinventá-lo criativamente, ou mesmo recusando-se a utilizá-lo.

0 despreparo do professor é alardeado pelo discurso oficial, pelos órgãos internacionais e pela mídia, que lhe atribuem toda a responsabilidade pela escolha inadequada do livro didático. Todavia, no caso apresentado, as conseqüências de uma negociação que se estabeleceu em parte por objetivos de mercado, os quais, em vez deprioritariamente educacionais, ficaram velados. Aos docentes coube administrar na sua prática cotidiana a organização dos saberes com os livros recebidos. Voltemos ao depoimento da Profa. Silmar:

Em 2002 eu dei aula para todas as $6^{\text {as }}$ séries e para uma sala de $8^{\mathrm{a}}$ série. Senti muito ter recebido o livro Brasil: uma história em construção, pois 
eu já vinha trabalhando com a História Temática e ela se desprende um pouco da questão cronológica. Ela vai à direção de você levantar um questionamento, de você pegar um tema e ver como ele permeia toda a História. Independentemente de século, de datas, enfim... porque o tema está presente em nossas vidas. Agora, no caso do Brasil, uma história em construção, el e foca o Brasil. Q ue é interessante? É. M as para uma 8á série eu preferia estar trabalhando com História Temática e, principalmente, focando em coisas do mundo contemporâneo. Coisa que infelizmente o livro didático não ajudou. A pesar disso, eu ainda consegui trabal har com o livro, mesclando com outros materiais. Agora, professores outros, que pegaram as outras salas de 8 a série, simplesmente não usaram os livros. Eu usava com textos complementares, e até com outros livros, porque a escola normalmente tem uma reserva de anos anteriores, e a gente trabaIhava um pouco com cada um. ${ }^{14}$

Podemos concluir, pelos dados apresentados e pela fala dos docentes que, muitas vezes, aspectos da materialidade dos livros didáticos interferem diretamentena sua prática pedagógica, atuando como um constrangimento que obriga o professor a reelaborar o desenvolvimento de sua prática em função do material recebido e, por vezes, alterando os saberes pedagógicos que circularão na sala de aula.

Procuramos demonstrar, então, que aspectos políticos e econômicos, subjacentes à circulação do livro didático, interferem diretamente na prática do professor, que se concretiza na sala de aula e, portanto, no currículo em ação!

CASSIAN O, Célia Cristina de F. The political and economical aspects of theHistory textbook circulation and itsimplications with thecurriculum. História, São Paulo, v. 23 (1-2), p. 33-48, 2004.

A B ST RACT: The article considers some aspects of the textbook circulation that precedes its ingress into the school, but interferes directly with the knowledge present at the classroom. It reveals the Brazilian public policies for the textbooks, in 2004, and analyses the interference of this policies on the curriculum through the History textbooks, adopted in the public school system of the city of Sao Paulo, during 2002.

KEYw O R D S: Textbooks; public policies; History education. 


\section{NOTAS}

${ }^{1}$ D outoranda da Pontifícia Universidade Católica de Santos- PU C-SP - CEP 05014001. f.cassiano@uol.com.br

${ }^{2}$ APPLE, M ichael W. Trabalho docente e textos. Porto Alegre: Artes M édicas, 1995, p.85.

${ }^{3}$ GIM EN O-SACRISTÁN, J. 0 currículo: uma reflexão sobre a prática. 3.ed. Porto Alegre:Artmed, 2000, p.89.

${ }^{4}$ LAJO LO, M arisa (org). 1996. Livro didático: um (quase) manual de usuário. In: Em aberto. INEP. v.16. no 69, pp. 3-7

${ }^{5}$ BATISTA. Antonio Augusto Gomes. Recomendações para uma política pública de livros didáticos. Brasília: M inistério da Educação. Secretaria de Educação Fundamental, 2001

${ }^{6}$ M EC. 1993. Plano decenal de Educação para Todos/ 1993 - 2003. Braślia: M EC. grifo meu.

${ }^{7}$ BATISTA, Antonio Augusto Gomes. Op. cit.

${ }^{8}$ M EC. 2001. Guia de livros didáticos. 5ạ a 8a séries. Brasília: M EC.

${ }^{9}$ SEE SP/CENP. Lendo eaprendendo. manual de orientação para a escolha de livros: PN LD 2001/2002. São Paulo: SEE/CENP, 2001, p. 7-8 (grifo do autor).

${ }^{10}$ MEC. 2001. Guia de livros didáticos. 5a a 8a séries. Brasília: M EC.

${ }^{11}$ Profa. Silmar, entrevista realizada em 10/1/2003.

12 M EC, 1993. Op. Cit, BATISTA, Antonio Augusto Gomes. Op. cit.; CHOPPIN, Alain. Las políticas de libros escolares en el mundo: perspectiva comparativa e histórica. In: PÉREZ SILLER, J. y RADKAU GARCÍA, V. (coords.): Identidad en el imaginario nacional. reescritura y enseñanza de la historia. M éxico: Instituto de Ciencias Sociales y Humanidades de la Universidad Autónoma de Puebla/El Colegio de San Luis y Georg Eckert Institut, 1998, p.169-180.

13 Profa. Daise em entrevista concedida em 23/01/2003 para Célia Cassiano.

${ }^{14}$ Profá. Silmar, entrevista concedida em 10/1/2003 para Célia Cassiano.

Artigo recebido em 06/2004. Aprovado em 09/2004. 